VIANNEY GONZÁLEZ LUNA

UNIVERSIDAD INTERCONTINENTAL

CIUDAD DE MÉXICO, MÉXICO

VIANNEYGONZALEZLUNA@GMAIL.COM

\title{
Ecosistema editorial y entorno público
}

\author{
Editorial Ecosystem and Public Environment
}

Resumen. La producción editorial ha transformado históricamente los aspectos culturales y sociales de la humanidad, esto ha sucedido en diversas formas y a través de múltiples formatos, lo que nos lleva a preguntarnos sobre el estado actual de la industria y los procesos que han sido transformados por los avances tecnológicos, así mismo el cambio en los lectores.

Ante estas variaciones nos cuestionamos cómo es que la materialidad de los textos se vuelve efectiva y transformadora en escenarios como el entorno público y sus instituciones, tema del que se ha hablado poco en el sentido de conformar procesos cada vez más asertivos, y es aquí donde intervienen dos principales factores, el trabajo de un editor profesionalizado y el del diseñador como mediadores para visibilizar la voz del estado.

Palabras clave: Diseño gráfico, edición institucional, Institución pública editora, sociología de los textos, procesos editoriales

Abstract. Editorial production has historically transformed the cultural and social aspects of humanity, this has happened in various forms and through multiple formats, which leads us to ask ourselves about how is the current state of the industry and the processes that have been transformed by the technological advances, likewise the transformation of the readers. Faced with these changes, we question how the materiality of the texts becomes effective and transformative in scenarios such as the public environment and its institutions, a subject that has spoken little in the sense of forming increasingly assertive processes, and this is where they intervene two main factors, the work of a professionalized editor and the designer as mediators to make the voice of the state visible.

Keywords: editorial processes, graphic design, Institutional edition, public publishing institution, sociology of texts.

Fecha de recepción: 25/03/2019

Fecha de aceptación: 11/05/2019

Cómo citar: González Luna, V. (2019)

Ecosistema editorial y entorno público.

RChD: creación y pensamiento, 4 (6), 1-10

DOI: 10.5354/0719-837X.2019.52614

Revista Chilena de Diseño,

RChD: creación y pensamiento

Universidad de Chile

2019, 4(6)

http://rchd.uchile.cl 


\section{Introducción}

El punto de partida de estas notas es mostrar una panorámica que sitúa el trabajo de dos actividades fundamentales en la transformación de la información que se genera en una institución pública, la Edición y el Diseño gráfico, actividades que están directamente relacionadas con el texto y su materialidad y las cuales no pueden ser percibidas como un acto automático e impersonal del lenguaje, cuya visión reduccionista ensombrece las actividades que pertenecen a la cadena de valor de los procesos editoriales.

Para establecer un antecedente al respecto de las actividades que realiza una institución pública sobre la comunicación de su quehacer, hay que concentrarse en dos aspectos principalmente, la divulgación de la investigación con subsidio del estado - a través de la visibilización de la información-y su efecto político con relación a la rendición de cuentas.

Es aventurado contar con una clasificación precisa de las instituciones públicas a partir de sus funciones como "empresa" editorial, para ello implicaría que se asumiera el trabajo editorial como un proceso complejo y lleno de incertidumbres que un profesional pudiera sortear por el conocimiento profundo del engranaje que compone dicho proceso, desde el planteamiento editorial hasta el lector final y el impacto que tuvo en él, a partir de su lectura; lo cual no pasa en entornos de este tipo, pues quien lleva a cabo estas labores son funcionarios públicos con otras especializaciones.

Con fines de tener una mejor comprensión de la presente postura, se define a las instituciones públicas con funciones editoriales, como instancias que reproducen en un sentido particular, la voz del Estado, sus valores intangibles y morales, con la responsabilidad de hacer uso eficiente de los recursos, a través de dos aspectos, las funciones políticas y las funciones explícitas. Las instituciones deberán examinar estrategias innovadoras de mediación con los lectores, de una forma distinta a la que se establecen en una editorial privada, ya que el objetivo en sí mismo no está en la búsqueda de márgenes de utilidad financiera, sino en el uso eficiente de los recursos públicos o en el cumplimiento de las funciones de la institución a las denominadas como funciones explícitas. Por lo tanto, para comprender mejor estos valores intangibles, será importante dimensionar, la estructura de la institución, y la autorrepresentación y con ello delimitar sus funciones como institución editora y los factores políticos con los que debe completar sus dimensiones estructurales y orgánicas (González, 2015).

Es por ello que establecer las responsabilidades dentro de este complejo proceso, requiere, también, delimitar el perfil de un editor institucional el cual se describe como un agente que hace que el volumen de datos generados se transforme en contenido y llegue al mayor número de personas posibles, cuidando quirúrgicamente la relación entre el contenido, su mediación y el impacto en su recepción. Su deber está en hacer funcionar los recursos públicos para fortalecer las competencias de los ciudadanos, y que además busque nuevas estrategias sostenibles para hacerse ver y generar los códigos de representación en función de apoyar la construcción de la hegemonía y legitimidad (González, 2017). En este sentido, acercar los libros a los lectores es una tarea relativamente fácil, el reto está en acercarlos a los no lectores, sin embargo, los editores esperarían que los que sí leen de forma cotidiana sean multitudes ya que fomentar la lectura, la alfabetización o conciliar ambas y enfrentarlo con el problema de pobreza en nuestro país, es un tema que requiere esfuerzos mayores y colectivos. 
Se mencionaron algunos planteamientos iniciales para entender el sistema editorial, la materialidad del libro, el contenido y su lector, así como los agentes contextuales de la sociedad, hace del libro un elemento de gran valor simbólico, pero ¿realmente creemos que todo gira en torno al libro y a su remuneración? Aunque no se duda de que sea el fin último de algunos editores, es posible considerar que la mayoría está dotado deontológicamente en función del ecosistema ${ }^{1}$ en el que se desarrolla, atendiendo a valores institucionales determinados, a contenido restringido, a función y participación política, a crisis económica y de identidad, a ser congruente y responsable de sus decisiones y como tema contemporáneo, a ser resilientes. Si bien una alternativa para mejorar los procesos, es ajustar los modelos de organización, dignificar el trabajo de los agentes relacionados, y ser eficaces en los procesos, sería comprender que esta actividad requiere la voluntad de todo el ecosistema.

La complejidad no tiene recetas. Cada institución, cada proyecto, cada obra y cada equipo editorial requiere un traje a la medida y la profesionalización en el área amplía el margen de asertividad.

En el ámbito público la coyuntura no es distinta a la de otras editoriales e instituciones públicas. El tema central es cómo hacer que el gran contenido que genera llegue al mayor número de personas, independientemente de si son lectoras o no. Esto también se refiere a un tema de ciudadanía, es decir, hay que considerar el rol político que constituye a una institución editora del Gobierno, que por sí misma tiene que hacer funcionar los recursos públicos en favor de fortalecer las competencias de los ciudadanos, y que además busque nuevas estrategias sostenibles para hacerse ver y generar los códigos de representación que apoyen a la construcción de la hegemonía y de la legitimidad, tema de controversia en la sociedad mexicana donde el Gobierno vive una crisis de credibilidad en sus instituciones.

Por todo lo anterior, el perfil del editor institucional exige un amplio conocimiento y sensibilidad sobre la vida pública de nuestro país para poder atender no solo las demandas culturales, sino también el crecimiento sostenido de México como funcionario público. El objetivo del editor institucional, como lo sugiere Frania Hall (2014), debe desarrollar organizaciones que sean capaces de expandirse y contraerse mientras se llevan a cabo proyectos tecnológicos. Esta afirmación es útil para el análisis de la actividad editorial, donde el editor debe concebirse como un gestor de información dispuesto a ampliar las coyunturas y explorar nuevas estrategias para los fines comunes, para ello debe tener en consideración algunos requerimientos estructurales para la gestión de la información como:

- Creación y mantenimiento de una estructura de información efectiva, visible y sostenible.

- Estrategia de gestión de datos para tener la capacidad de captura de datos correctos y actualizarlos constantemente.

- Fortalecer la plataforma genérica existente y generar vínculos de gestión de información para las áreas editoras y que de ellas se deriven productos específicos.

- Ampliar de forma interna o externa los departamentos de tecnología para crear sistemas de codificación, taxonomías, protocolos y estándares para información técnica. Con ello se desarrolla la base de datos con características institucionales para generar condiciones óptimas para crear productos en distintos canales e, incluso, para desarrollo de estrategias y programas personalizados que se dirijan a usuarios clave.
1. La analogía del sistema editorial con el término de ecosistema, tomado de las ciencias biológicas, viene a cuenta por lo peculiar de su naturaleza y los sistemas naturales que lo conforman, donde las partes y el todo, interactúan de forma constante, unas forman patrones dentro de redes complejas y cada parte asume sus funciones dentro del contexto, sin hablar de ellas como unidades independientes, privilegiando la diversidad, lo que garantiza la supervivencia de dicho ecosistema. 
2. El marco lo describe Bhaskar como un término

general para determinar el contenedor o canal

material o digital que parte de un sistema integral entre contenido, continente y visibilización,

además de agrupar estos conceptos entrelazados, también los aspectos materiales e inmateriales del contenido que se presenta. (Bhaskar, 2013:91-105).
- Esta ampliación genera la necesidad de integrar un medio de atención al usuario tanto interno como externo.

- Generar además unidades informativas especializadas para administrar servicios particulares como boletines diarios de noticias.

- Integrar un solucionador de problemas y apoyo a los servicios de informática con hardware y software, para corrección de errores, flujo de información interinstitucional, control de calidad y certidumbre en la funcionalidad.

El éxito de estas intervenciones en el sector de instituciones editoras está en el avance efectivo y eficiente de su base de datos, dado que su información la convierte en un valor simbólico diferenciador en las instituciones públicas no académicas.

El perfil del editor, para estas instituciones, deberá transformarse en función del crecimiento, su utilidad de la base de datos institucional, incrementando las competencias del editor dirigidas a la flexibilidad con la que usará el valor simbólico de la institución.

El editor institucional con este valor agregado puede tomar decisiones en el uso de la base de datos, del mercado, del desarrollo de productos y en el cuidado de los derechos de autor y con ello generar estrategias para responder a los cambios en el mercado. El editor adquiere, entonces, un valor extendido y por lo tanto una formación holística responsable con el contexto social, debido a que uno de sus objetivos es contribuir a la buena imagen y reputación de su sello editorial.

Las contribuciones bajo el esquema de los procesos anteriores a la migración de impresos a digitales no deberán verse como un impedimento, ya que son un activo de la institución que puede ser base de un nuevo panorama de reciclaje en la información para generar comparativas de apoyo a nuevos productos, ofreciendo estos como una visión de bibliotecas o archivos y considerar modelos de venta por paquetes, suscripciones, licencias o pagos por consulta.

\section{El contenido como eje de la teoría de la edición}

El conocimiento sobre el contenido es fundamental como elemento subjetivo en la elaboración de políticas públicas editoriales, lo que permite mantener objetivos institucionales entorno a la vinculación cotidiana entre sociedad, academia y gobierno.

El dominio sobre el comportamiento estadístico del contenido, es decir cómo llega, cómo se entiende, quién lo manda, cómo se almacena, cuándo, qué genera, a quién sirve y cómo llega a quien tiene que llegar, nos permite tomar decisiones y mantener en perspectiva el marco $^{2}$ o canal en el cual se hará visible el contenido, tomando en cuenta las implicaciones y el impacto que generarán estas variantes, a fin de producir experiencias pregnantes en la relación del contenido con su marco y que, como afirma Bhaskar (2014): "Nunca encontramos contenido puro sin mediación".

Además dependemos de la interpretación del contenido que a su vez requiere de la variante particular que le otorga el marco, sin embargo, nuestra inquietud como editores nos enfrenta a reducir incertidumbres para predecir, a través de modelos estratégicos, los niveles de interpretación y por lo tanto, intervenir directamente en el tratamiento de contenidos para entender las interacciones entre texto y lector, es decir, su recepción. Para ello, se elaboran hipótesis para entender las interacciones hacia cómo es 
que será recibido el contenido y cómo será posible delimitar las variantes o componentes que contribuyan a construir y moldear las experiencias de la obra que por sí misma requiere de metacompontentes -o como lo plantea Gérard Genette (1997) paratextos y epitextos-y son estas las herramientas utilizadas por la mercadotecnia.

Los modelos para facilitar la recepción de contenido con la industria editorial se han dirigido para obtener en el intercambio un valor económico, sin embargo, en las instituciones públicas editoras el intercambio se da a cambio de la acumulación de capital simbólico que beneficia al valor político, social o cultural. Dentro de la dimensión política de la recepción, se debe considerar que el intercambio tradicional se da por la persuasión donde el receptor responde a los acuerdos previos que ha desarrollado él mismo, sobre la personalidad de su interlocutor, y que en su afán de comunicación o expansión de ideas, el interés del interlocutor será fortalecer las competencias en los ciudadanos (en el marco de la edición institucional); mientras procura que el canal de comunicación esté sustentado por interferencias o mediaciones bien programadas con el fin de evitar el ruido que evita la configuración de su objetivo. Los elementos que la figura de la institución editora requiere para obtener los objetivos y garantías de lo que recibirá el destinatario son:

a) El pacto de lectura en la que la instancia editora se autodetermina como institución pública, generadora y divulgadora de conocimiento.

b) Su discurso con palabras clave que también son conocidas por el receptor y apoyan a la búsqueda e interacción que requiere el receptor.

La institución con ello evidencia los recursos de lenguaje que garantiza el diálogo entre los agentes, a favor de la construcción de una dimensión macroestructural, donde la interacción provoca que el sujeto sometido a la socialización constituya una significación a la conformación sociopolítica del conocimiento. La inclusión de las nuevas tecnologías como transformadoras en los hábitos de lectura y en comportamientos culturales arroja diferentes datos estadísticos sobre la cantidad, el contenido y su función. Los datos que abordan estas tres categorías hablan sobre la magnitud o trascendencia de la información y sobre la frecuencia con la que se practica la lectura en un lapso de tiempo determinado; así mismo, se estima el valor del tipo de material que consume la mayoría de los lectores y la funcionalidad que tiene al ubicar el fin para el que fue adquirida dicha lectura.

Al ser la frecuencia y la intensidad las que determinan principalmente la categoría del lector, se puede hacer una taxonomía sobre los niveles de lectura, primaria, de inspección, sintética, analítica y comparativa.

La labor del editor se diversifica, e inherente a este fenómeno, se debe considerar reforzar las competencias para llegar a los lectores potenciales, pero especialmente a los que consumen productos digitales; a su vez generar mejores programas ejecutivos que consideren un plan de negocio vinculando a las Tecnologías de la Información y la Comunicación (TIC) y la producción de libros tradicionales, a través de nuevas estrategias transmedia, integración de mejores instrumentos jurídicos y siempre manteniendo un enfoque sostenido.

Esto lleva a la siguiente reflexión en cuanto a la actividad del editor: ¿es únicamente un productor de libros? La realidad ha rebasado el planteamiento sobre lo abstracto que resulta el concepto del editor al verse implicado 
en las transformaciones tecnológicas, que durante siglos ha sido un tema de evaluación para aquellos mediadores de información, el cual lo ha obligado a adquirir una visión fractal de sí mismo y su rol en el campo editorial. Las habilidades del editor contemporáneo muestran una sensible transformación al ocuparse de las coyunturas que se generan en conjunto a su simple deseo de transmitir conocimiento y generar ganancias al respecto, lo cual lo ha obligado a convertirse en un artesano de la información, donde moldea y estructura conocimiento, datos e historias de forma plástica y elástica e incluso lo lleva a la desmaterialización del libro, muestra de ello, los libros digitales. El editor está en permanente diálogo entre tradiciones y nuevas prácticas discursivas.

El proceso de desmaterialización del libro obliga al editor contemporáneo a pensar en otros paradigmas como la ecología editorial, es esta una metáfora que se relaciona con el planteamiento de Carlos Alberto Scolari (2015) donde determina que las tecnologías de la comunicación generan ambientes que afectan a los usuarios. Esto quiere decir que generan un entorno propicio para abrir nuevos canales de acceso a contenidos en distintos formatos o generando un diálogo transmedia y que, basado en los conceptos entre lo orgánico (vida, supervivencia y reproducción) y lo técnico (orden, control, eficiencia y poder), conforman un ecosistema de producción donde el editor evoluciona dentro del ambiente manteniéndose invisible en ciertos procesos y finalmente, se transforma por las percepciones de diversos agentes, haciéndolos visibles y a demandar su involucramiento. Estos agentes moldean los instrumentos de comunicación y al mismo tiempo moldean la estructura del editor.

Las instituciones públicas en México, como parte de sus funciones explícitas, tienen diversos canales de comunicación sobre la información que generan, concentran y divulgan, por ejemplo, los libros, materiales didácticos, videos, conferencias, pláticas, talleres de gestión, redes sociales, entre otras. Por ello, establecer una serie de sistemas que determinen los procesos que consideran a los insumos de datos hasta el producto terminado, podrán derivar en un sistema de control muy útil, mismo que dará un panorama general y trazará rutas de acción para la toma de decisiones en la producción editorial. Deberá considerar las variables del entorno a nivel macro y micro, así como las variables operativas y estratégicas. El tamaño del sistema que se genera a partir de las publicaciones, va a determinar el volumen de operación. Con esta dinámica, el acceso a la información que en ellos se publica, la consulta se complica para ciertos públicos que pueden serles útiles los contenidos, como los estudiantes o los lectores potenciales fuera del entorno urbano.

\section{Gestión de la información}

Para integrar a los canales de comunicación emergentes una mejor estrategia de difusión, es importante considerar el tratamiento de la información con apoyo de las nuevas tecnologías y con ellos maximizar el impacto en la sociedad, para permear en ellas la información que produce la institución con herramientas de interoperabilidad para su distribución, y así generar etiquetas que apoyen la búsqueda y metadatos para poder insertarlos en índices de las principales bibliotecas digitales.

Las TICS como herramientas informativas y los servicios asociados a ellos han sido configuraciones variables en la construcción social que se ha basado en tecnologías evolutivas, ello provoca conflictos estratégicos entre los 
distintos agentes industriales e institucionales, así como los usuarios interesados en la gratuidad de los productos, público objetivo que representa el sector más activo en busca de una nueva herramienta de consulta.

Las TICs han dado lugar a trabajos de investigación en temas sociales y ciencias humanas y han sido impulsadas con una perspectiva interdisciplinaria como la telemática, microinformática, web semántica y la digitalización de documentos, los mismos que se han orientado a las formas de consumo. Para el análisis de un esquema de adaptación para la gestión de la información, habrá que considerar las especificaciones del contenido y de la misma forma, ubicarlos en una temporalidad específica a corto y largo plazo en favor de la innovación, por lo tanto, en correspondencia a la gestión de la información, derivará en la amplitud del uso de los medios y su relación con los usuarios, lo que contribuye al incremento de la mediatización digital. La Estrategia Digital Nacional, publicada en noviembre de 2015, sirve como herramienta para desarrollar la Reforma a la Constitución Política de los Estados Unidos mexicanos en materia de Telecomunicaciones y Competencia Económica, con ello, se pretende guiar las acciones dirigidas a acercar las tecnologías a la sociedad, empresas y entre las instituciones del Gobierno, para fomentar la innovación, la productividad y eficiencia de servicios públicos. Uno de los habilitadores principales de esta estrategia sobre el acceso a los datos se refiere al uso de información generada por las instituciones públicas en formato abierto. El valor de los datos abiertos está en la capacidad de fomentar nuevos servicios e investigación a partir de ellos, relacionándolos con otras entidades entre sí. La política de datos abiertos es un primer ejercicio en colaboración con la sociedad para construir y generar mejores políticas públicas en torno a las necesidades nacionales.

\section{La materialidad a través del diseño}

La influencia del diseño se ha dado ineludible en el espacio social, en un ininterrumpido viaje de ida y vuelta, construido bajo discursos y con estructuras retóricas que han contribuido en la persuación de los auditorios bajo ese espacio. Las características exógenas y endógenas del diseño han de darse a partir de lo que sucede "afuera", es decir, en el contingente de factores que componen "lo social" para regresar al diseño y reproducirse nuevamente. Para que este fenómeno se dé, los factores implicados están relacionados con la traducción, la importación, la interpretación y la "construcción de lo propio", así mismo el estudio de conceptos generales como posmodernidad, democracia y "cultura popular" son parámetros que plantean diversos problemas a la disciplina del diseño, pero que abren una serie de posibilidades amplias al trabajo del diseñador como agente interdisciplinario, como espacio cotidiano de interacción con otros actores sociales.

Tal como sería la intención del autor y la separación con el significado de su obra, sus medios de transmisión, recepción e interpretación como un proceso colectivo hacia la construcción de sentido, es decir, la sociología de los textos: "entendamos la disciplina que estudia los textos como formas registradas, así como los procesos de su transmisión, que incluyen su producción y su recepción" (McKenzie, 2005, p. XX), donde señala de forma categórica que los bibliógrafos deben tener como premisa demostrar que las formas repercuten en el significado y los procesos sociales de transmisión y, por otro lado: 
3. Como lo plantea Foucault. "[...] El problema previo es la relación con el otro como mediador. El otro es indispensable en la práctica de uno mismo para que la forma que define esta práctica alcance efectivamente su objeto, es decir, el yo" (Foucault, 1996, p. 55).
De manera completamente específica, se ocupa de los textos no librarios, sus formas materiales, versiones textuales, transmisión técnica, control institucional, sus significados tal cual como son percibidos y sus repercusiones sociales. Se refiere a una historia del libro y de hecho, de todas las formas impresas, incluidas los textos efímeros como registro de los cambios culturales. (McKenzie, 2005).

Sobre esta última afirmación dirijo esta perspectiva, al respecto de entender a la sociología de los textos como factor de transformación cultural y en ese sentido dirigir la atención hacia la actividad del Estado como mediador de información a través de las instituciones públicas.

La incidencia del Diseño gráfico en la sociedad ha transformado en gran parte nuestro quehacer cotidiano, ha sido el input de transformación sobre la estetización de la vida cotidiana que marca un importante punto de inflexión entre modernidad y posmodernidad (Maffesoli, 2014).

El Diseño gráfico es una disciplina social y humanística que estructura, mediante procesos discursivos, la planeación, el conocimiento y la realización de comunicaciones visuales. Esta disciplina está fundamentada en técnicas, métodos y teorías para incidir a través de las imágenes sobre la sociedad y sus necesidades.

El contexto social en el que se ubica actualmente la actividad del Diseño gráfico ha sido resultado de importantes transformaciones y debates sobre la objetivación per se de la disciplina, por un lado estas transformaciones ampliaron las posibilidades de hacer "más simples" la ejecución material de los productos gráficos gracias a la Revolución Tecnológica, pero a su vez transformaron las necesidades de comunicación visual junto con otros factores, como los políticos, económicos y sociales.

Por otro lado, el gremio profesional y académico centra su atención en impulsar el debate sobre la metodología y el perfil idóneo del diseñador gráfico, en función de fortalecer el reconocimiento social sobre la complejidad de una disciplina como ésta, que relaciona herramientas teóricas de comunicación visual con la técnica y en conjunto sustenten un sistema para alcanzar objetivos que le permitan relacionar sus propuestas con la sociedad y la cultura, a través de sus propios recursos discursivos y su capacidad de interpretar y pensar en el otro3. Es por ello que el diseñador gráfico colabora en la innovación -concepto vinculado a la identificación y solución de problemas complejos que requieren la colaboración de diversas disciplinas- de estrategias comunicativas a través de recursos discursivos, icónicos, tipográficos, plásticos, entre otros.

El Diseño, aunque no ha alcanzado un valor público cultural, sí ha llegado a incertarse en temáticas culturales, tiene virtudes propias que no han sido mostradas explícitamente. Estas virtudes según Bonsiepe (2012), no pueden pertenecer al ámbito privado, irremediablemente se convierten en tema del ámbito público. Los intereses que enumera el autor, con relación a una opinión de Italo Calvino, realizada en el Congreso de Aspen (Colorado) de 1989, sobre literatura, son temas que Bonsiepe relaciona con las características del Diseño.

En esta intervención, Calvino enumera dos virtudes inherentes a los proyectos de Diseño delimitados a ciertos intereses básicos, relacionados con la interpretación actual del Diseño, confrontado con las estructuras del siglo XX, y por otro lado, los cuestionamientos al respecto de su propósito, es decir a qué intereses atiende, cómo se delimita su intervención y la 
pertinencia que tiene este sobre la efectividad comunicativa.

El perfil del diseñador se ha ido transformando abruptamente, y fluctúa entre dos aspectos, por la eficiencia en las habilidades gráfico expresivas o en la "intelectualidad", para precisar la importancia de construir una personalidad dual, pues a veces se deberá hacer visible a la sociedad el pensamiento estratégico y en otras ocasiones reservarse esa intelectualidad para hacerse ver como talentoso artista -retomando el término de Antonio Gramsci- el cual lo define como "intelectual orgánico" el cual se refiere al uso de todos sus recursos gráficos-expresivos y técnicos en el marco de las instituciones sociales. En el Diseño, a diferencia de otras disciplinas, ha sido poco su registro escrito sobre su papel en la sociedad. Diseñar y escribir acerca del Diseño, apenas comienza a aparecer al diseñador y a su formación una actividad fundamental. En ese sentido, podría ser de utilidad para establecer el papel que ocupa en la sociedad y su pertinencia en el entorno público y como consecuencia de ello, en el anclaje de dichos temas hacia políticas de Diseño, pues toca a la administración pública y a los políticos, el cuidado de la propiedad pública, es decir, la calidad de los servicios, la atención al detalle de los mismos, al cuidado del espacio público y a la divulgación y comunicación de lo que hace y publica o cómo se establece aquí en sus funciones explícitas

\section{Conclusiones}

Para concluir, hablar sobre el rol de una institución pública o privada, y sus interacciones internas en el trabajo del editor y el diseñador, se extiende sobre múltiples significaciones y disciplinas, así como entender el objetivo de las mismas. El término de institución descrito por Beatriz Zepeda (2012) está dividido por dos acepciones, una es un patrón general de categorización de la actividad y otra un arreglo particular socialmente construido, formal o informalmente organizado, donde en ambas se define un conjunto persistente de reglas que describen actividades y comportamientos, limitan la actividad y moldean las expectativas debido a que las metas y valores que persiguen son identificadas de alguna forma por la sociedad. De esta forma, moldeadas por la misma con su participación y el cambio que se manifestará gradualmente por los valores sociales dominantes del contexto, por lo tanto, las instituciones se convierten en instrumentos de difusión de nuevos valores sociales; todo esto está dirigido hacia la construcción nacional y en dirección a la creación de instituciones, reforzando el objetivo de estimular la lealtad hacia la nación, al inculcar tanto un sentido de comunidad como la identificación frente a otras naciones. Valiéndose de este tipo de valores simbólicos, las élites (grupos de poder) hacen uso de la infraestructura institucional del Estado que proporcionan a sí mismos recursos materiales necesarios para su supervivencia y con ello el establecimiento y reproducción de valores que promueven la idea de nación.

Aún cuando el control del Estado por medio de sus instituciones pareciera ser el mejor medio para difundir su idea de nación, no siempre es un sistema rígido y absoluto, sino que estas entidades recurren a la negociación con la sociedad civil con lo que llama el "poder mediante".

Para estructurar una efectiva mediación entre las instituciones y la sociedad, estas entidades recurren a modelos de comunicación donde los profesionales del Diseño gráfico son indispensables para la conceptualización de la comunicación visual a través de los medios de información en diversos formatos o soportes y con ello contribuir a la solución de problemas, en función de elevar la calidad de vida en la sociedad. 


\section{Bibliografía}

American Psychological Association, (2010). Manual de publicaciones. Tercera edición, México: Editorial el Manual Moderno.

Bashkar, M. (2014). La máquina de contenido. México. Fondo de Cultura Económica.

Biro, S. (2002). "Historia de la ciencia para divulgadores". En Antología de la divulgación de la ciencia en México. México: Dirección General de Divulgación de la Ciencia, Universidad Nacional Autónoma de México (UNAM).

Bourdieu, P. (2011). Capital cultural, escuela y espacio social, México: Siglo XXI editores.

Bonsiepe, G. (2012). Diseño y crisis, Valencia: Campgràfic editorial.

Calvo, M. (2003). Divulgación y periodismo científico: entre la claridad y la exactitud, México: Dirección General de Divulgación de la Ciencia, Universidad Nacional Autónoma de México.

Callenbach, E. (1999). La ecología, Madrid: Siglo XXI editores.

Cavallo G. y R. Chartier (coord.). (2011). Historia de la lectura en el mundo occidental. México: Taurus.

Cohen, S. (2011). Guía esencial para resolver dudas de uso y estilo. México: Planeta.

Colom Cañellas A. J. y J. M. Touriñán López. (2009). "La lectura en el siglo XXI". Nuevas tecnologías y la nueva condición lectora. Autores y Actores de la Educación, México: ILCE.

Cosío Villegas, D. (1976). Memorias. México: Joaquín Mortiz.

Chartier, R. (1992). El mundo como representación. Estudios sobre historia cultural. Barcelona: Gedisa Editorial.

Etkin, J. y L. Schvarstein. (1992). Identidad de las organizaciones. Invariancia y cambio. Buenos Aires: Paidos.

Febvre L. y H. J. Martin. (1962). La apariencia del libro (Agustín Millares Carlo trad.). México: Fondo de Cultura Económica.

Foucault, Michel. (1996). Hermenéutica del sujeto. La Plata, Argentina: Altamira.

Gazkell, P. (1999) Nueva introducción a la bibliografía material. Gijón: Trea.

Gennette, Gerard. (1997). Paratexts: Thresholds of Interpretation. Cambridge University Press, Cambridge.
González-Luna, V., (2017). "La edición en las instituciones públicas: Conabio estudio de caso. Idónea Comunicación de Resultados". En Antecedentes, pp. 7-10. México: Universidad Autónoma Metropolitana. Hall, F. (2014). El negocio de la edición digital. México. Fondo de Cultura Económica.

Kloss Fernández del Castillo G. (2009). Entre el diseño y la edición. Tradición cultural e innovación tecnológica en el diseño editorial. México: Universidad Autónoma Metropolitana.

Ley Federal de Derecho de Autor. (1996). Publicada en el Diario Oficial de la Federación el 24 de diciembre.

Maffesoli, Michel. (2014). El regresar del tiempo. Formas elementales de la posmodernidad. México: Siglo XXI Editores.

Martínez, M. (2012). Evaluación cualitativa de programas. México: Editorial Trillas.

Mckenzie, D. F. (2005). Bibliografía y sociología de los textos (F. Bouza (trad.). Madrid: Akal Ediciones.

Merlo, R. y M. F. Abad García. (2008). “Revistas open access: características, modelos económicos y tendencias". BID: textos universitaris de biblioteconomía i documentació, juny, núm. 20. Recuperado de http:// bid.ub.edu/2omeler2.htm.

Miége B, M. Becerr, Lorenzo Vilches et al. (comp.). (2010). Mutaciones de lo visible. Comunicación y procesos culturales en la era digital. Buenos Aires: Paidós.

Universidad Autónoma del Estado de México. (2005). Política editorial de la UAEM: fundamentos y procesos. Toluca: UAEM.

Scolari, Carlos. (2015). Ecología de los medios. Entornos, evoluciones e interpretaciones. Barcelona: Gedisa.

Zaid, G. (1985). Daniel Cosío Villegas. Imprenta y vida pública. México: Fondo de Cultura Económica.

Zavala Ruiz, R. (2009). Sugerencias de redacción. México: Universidad Autónoma Metropolitana.

Zavala Ruíz, R. (2012). El libro y sus orillas. México: Fondo de Cultura Económica.

Zepeda, B. (2012). Enseñar la nación y la institucionalización de la idea de la nación en México de la Reforma (1855-1876). México: Fondo de Cultura Económica/Conaculta. 